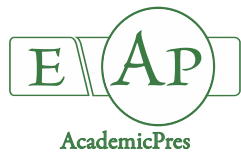

\title{
Presumptive Relationship between Oxidoreduction Potential and Both Antibacterial and Antioxidant Activities of Herbs and Spices: Oxidoreduction Potential as a Companion Tool for Measuring the Antioxidant Activity
}

\author{
Duried ALWAZEER ${ }^{1 *}$, Sally DHAM ${ }^{2}$ \\ ${ }^{I}$ Iğdır University, Faculty of Engineering, Department of Food Engineering, Research Center for Redox Applications in Foods (RCRAF), Iğdır, \\ Turkey; duried.alwazeer@igdir.edu.tr (*correspondingauthor) \\ ${ }^{2}$ Consultant Food Engineer, Jacksonville, Florida, USA; sallydham@hotmail.com
}

\begin{abstract}
Antibacterial and antioxidant activities form an essential component of the bioactive properties of plant products. The antibacterial and the antioxidant properties of three types of aqueous extracts of four herbs and spices were evaluated. While the total phenolic content, DPPH radical scavenging activity and oxidoreduction potential methods were used for the antioxidant properties determination, the inhibition diameters of extracts toward the growth of Staphylococcus warneri, Bacillus cereus, Enterobacter cloacae and Proteus vulgaris were evaluated. Although the phenolic content did not correlate with the antibacterial activity of plant extracts, it linearly correlated $\left(\mathrm{R}^{2}=0.827\right)$ with DPPH scavenging activity of the studied plants following the order: sumac $>$ ginger $>$ rosemary $>$ cinnamon. The oxidoreduction potential values linearly correlated with both the phenolic content $\left(\mathrm{R}^{2} \approx 0.88\right)$ and DPPH scavenging activity values $\left(\mathrm{R}^{2} \approx 0.96\right)$. The oxidoreduction potential could be proposed as a useful companion tool combined with other techniques when determining the antioxidant activity of plant extracts and food products is considered.
\end{abstract}

Keywords: antibacterial activity; antioxidant activity; herbs and spices; oxidoreduction potential; phenolic content

\section{Introduction}

Herbs and spices have been traditionally added to many foods and used in folk medicine since ancient times by different nations. Their uses were for many objectives such as the improvement of the sensorial properties and the extension of the shelf life of food product by decreasing or eliminating the microbial load in product (Negi, 2012). These plants are characterized by their antimicrobial and antioxidant activities thanks to the richness of chemical composition in active compounds such as organic acids, phenolic compounds, essential oils, sulfur compounds and pigments (Proestos et al., 2005). Many researches have been conducted to characterize these active compounds and their antioxidant and antimicrobial activities as well as their potential applications in pharmaceutical and food products.

The exploring of natural sources of bioactive molecules requires reliable methods for the antioxidant activity evaluation in product (Shahidi and Zhong, 2015). Different methods and tools used for measuring antioxidants activity have remarkably advanced during the last few decades.
Many of these methods have been proposed for the determination of antioxidant activities using different mechanisms and instruments (Shahidi and Zhong, 2015). The difference between these methods is characterized by the mechanism of action, the active reagent applied and the instrument used to $\log$ and interpret the data. The free radicals techniques are widely used in in vitro antioxidant analysis by researchers thanks to their simplicity and ease of manipulation. Among the free radical methods, the DPPH scavenging activity as well as the phenolic content are the commonly used ones (Alam et al., 2013).

Oxidoreduction potential is defined as a physicochemical parameter that determines the oxidizing/reducing properties of the medium / product. Its value depends on the chemical composition of the food / medium i.e. thiol-containing amino acids, peptides, proteins, vitamins, dissolved oxygen, free radical content, phenolic compounds, content of reduced or oxided couples such as $\mathrm{Fe}^{+2} y^{+3}$ and reducing sugars, the $\mathrm{pH}$ value, the temperature, and the dissolved oxygen content (Alwazeer $e t$ al., 2003). 
Although the biological activity of plants was widely studied in the literature but a less works were conducted on the presumed relationship between phenolic content and both the antibacterial and antioxidant activities of herbs and spices extracts (Shan et al., 2007). A relationship assumed between both antioxidant and antibacterial activities and oxidoreduction potential was our first question to investigate. Another question was about the possibility of application of the oxidoreduction potential measurement as a supplementary method when the antioxidant activity is envisaged. To test these hypotheses, we evaluated different analytical measurements of the antibacterial and antioxidant activities for different types of plants and extracts.

The aims of the present study were to evaluate the antibacterial and the antioxidant activities of some herbs and spices commonly used in food preparation for the research of a relationship assumed between the oxidoreduction potential values and both the antimicrobial and the antioxidant activities. The possibility of using the oxidoreduction potential method as a companion tool for the antioxidant properties measurement of extract/product was also investigated.

\section{Materials and Methods}

\section{Plantmaterial}

Sumac (Rhus coriaria L.) fruits, rosemary (Rosmarinus officinalis L.) leaves, cinnamon (Cinnamomum zeylanicum) barks and ginger (Zingiber officinalis) roots were purchased from a local supplier in dried form.

\section{Chemicals}

2,2-Diphenyl-1-picrylhydrazyl (DPPH)(Aldrich, USA), gallic acid (Lobachemie, India), sodium carbonate (Merck, Germany), glycerol (Merck, Germany), methanol (HPLC grade) and Folin-Ciocalteu (Merck, Germany) reagents were used for carrying out the assays. discs

Microorganisms, growth media and standard antibiotic

A total of four foodborne bacteria were kindly provided by the Department of Microbiology, Faculty of Medicine, University of Homs, Syria. These strains of bacteria were used for antibacterial tests. The test bacteria included Grampositive Bacillus cereus and Staphylococcus warneri, Gramnegative Enterobacter cloacae and Proteus vulgaris. Muller Hinton Agar (Biolab, Hungary) and Muller Hinton Broth (Oxoid Ltd, England) were used in the antibacterial screening test. Gentamicin and Penicillin discs (Oxoid, England) have been used in this study as a standard antibiotic. In preliminary studies, Gentamicin was found to be active against Enterobacter cloacae and Proteus vulgaris, while Penicillin was active against Bacillus cereus and Staphylococcus warneri.

\section{Preparation of plant materials prior to extraction}

The dried plants were kept in a refrigerator for no longer than three days prior to extraction. Before extraction, the plants were milled into a fine powder using a home mill.

\section{Extraction and preparation of aqueous extracts}

Five grams of each plant material were put in an Erlenmeyer, and then $100 \mathrm{~mL}$ of distilled water was added. Three extraction methods were employed: (1) maceration in water at room temperature for 24 hours, (2) maceration in water at $50^{\circ} \mathrm{C}$ for 24 hours and (3) boiling in water for 2 min. The extracts were filtered using Whatman No. 4 filter paper (Whatman International, UK). The filtrated extracts were then concentrated to the tenth of its volume $(1 / 10)$ using vacuum drier at $50{ }^{\circ} \mathrm{C}$ (Fratelli Galli, Italy). The obtained extracts were stored in a freezer at $-18^{\circ} \mathrm{C}$ until use. The $\mathrm{pH}$ of all samples was determined with a combined $\mathrm{pH}$ electrode (Inlab 427, Metler-Toledo).

\section{Determination of antibacterial activity}

Preparation of extract-and standard-loaded discs

Filter paper discs (Grade 54, diameter $6 \mathrm{~mm}$, Whatman International, UK) were autoclaved at $121^{\circ} \mathrm{C}$ for $20 \mathrm{~min}$ and oven-dried at $40{ }^{\circ} \mathrm{C}$ overnight. Each aqueous extract (20 $\mu \mathrm{l})$ was loaded on a sterile filter paper disc. All impregnated discs were dried in sterile glass Petri dishes placed in an oven at $30^{\circ} \mathrm{C}$ for $20 \mathrm{~min}$. The discs were then allowed to condition to room temperature before using in the antibacterial test.

\section{Screening of antibacterial activity of plant extracts}

The antibacterial activity of extracts was determined by the disc agar diffusion method. Sterilized molten Mueller Hinton agar $(20 \mathrm{ml})$ was dispensed to each sterile disposable Petri dish (diameter $9 \mathrm{~cm}$ ) and allowed to solidify. Microbial suspension $(100 \mu \mathrm{l})$ containing approximately 1.0 $\times 10^{7} \mathrm{CFU}$ was spread evenly onto the surface of the solidified medium. The plates were allowed to dry for 15 min before the test discs were placed at equidistance from each other. Each plate consisted of one standard antibiotic disc and three other discs impregnated with various extracts. After standing for $30 \mathrm{~min}$, the Petri dishes were incubated in an inverted position at $37^{\circ} \mathrm{C}$ for 18 to 24 hours. The diameter of the zone of inhibition $(\mathrm{mm})$, defined by the clear area devoid of growth, was measured twice and compared to the diameter of the inhibition zone of the standard antibiotic in the same Petri dish.

\section{Determination of the antioxidant activity}

Determination of total phenolic content

The amount of phenolic compounds in the extracts was determined by the Folin-Ciocalteu colorimetric method (Macheix et al., 1991). Determinations were carried out in triplicate and calculated from a calibration curve obtained with gallic acid. The total phenolic contents were expressed as $\mathrm{mg}$ gallic acid equivalents ( $\mathrm{mg} \mathrm{GAE} \mathrm{g}^{-1}$ extract).

\section{Determination of DPPH free-radical scavenging activity}

Antioxidant activity of the prepared extracts was determined with 2,2-diphenyl-1-picryl-hydrazyl (DPPH) assay (Singh et al., 2002). The free-radical DPPH was used as an oxidizing molecule to be reduced by the antioxidant compounds present in the extracts. The extracts were dried at $50^{\circ} \mathrm{C}$ using vacuum dryer (Fratelli Galli, Italy). One gram of dried extract was dissolved in $100 \mathrm{~mL}$ methanol. The same volumes of methanolic dissolved samples and DPPH 
508

solution $(60 \mu \mathrm{M})$ were vortexed together. The final solution was allowed to react in the dark for $30 \mathrm{~min}$. It was then centrifuged $(5500 \mathrm{rpm}(1165 \times \mathrm{g})$, Engelsddre/lepzig DDR-7123 Centrifuge, Germany) for 15 minutes. The absorbance of the supernatant was measured at $517 \mathrm{~nm}$ with a UV spectrophotometer (Analitica, Germany). The tests were carried out in triplicates. The DPPH free-radical scavenging activity was calculated by the following formula:

DPPH free radical scavenging activity $(\%)=\left[\mathrm{A}_{0}-\mathrm{A}_{1}\right] /$ $\mathrm{A}_{0} \times 100$

Where $A_{0}$ is the absorbance of the control solution containing only DPPH after incubation and $A_{1}$ is the absorbance in the presence of plant extract in DPPH solution after incubation.

\section{Determination of oxidoreduction potential values}

The oxidoreduction potential (Eh) value of extracts was measured with a combined redox electrode (Pt4805-DXK, Metler-Toledo, France) referred to the $\mathrm{Ag} / \mathrm{AgCl}$ system and connected to a redox-controlled interface (Consort 835 , Belgium). The Eh values were calculated according to Jacob (1970)(Jacob, 1970): $\mathrm{Eh}=\mathrm{E}_{\mathrm{m}}+\mathrm{E}_{\mathrm{r}}$; where Eh is the electrode potential referred to the normal hydrogen electrode, $\mathrm{E}_{\mathrm{m}}$ is the measured potential, and $\mathrm{E}_{\mathrm{r}}$ is the potential of the reference electrode $(\mathrm{Ag} / \mathrm{AgCl})$. The Eh values at $\mathrm{pH}=7\left(\mathrm{Eh}_{7}\right)$ were obtained after correcting Eh values according to the $\mathrm{pH}$ value of the extract as follows:

$\mathrm{Eh}_{7}=\mathrm{Eh}-59\left(7-\mathrm{pH}_{\mathrm{m}}\right)$; where $\mathrm{pH}_{\mathrm{m}}$ is the measured $\mathrm{pH}$ value of the extract.

Data and statistical analysis

All experiments were performed in different sets, with each set in triplicate. Statistical analysis was performed for ANOVA (Analysis of variance). Values of $P$, which were $\leq$ 0.05 , were considered significant.

\section{Results and Discussion}

\section{Antibacterial activity of aqueous extracts of plants \\ Antibacterial activity of aqueous extracts of sumac}

Table 1 shows while the maceration $50^{\circ} \mathrm{C}$ extracts has no effect against Enterobacter cloacae and Proteus vulgaris; this extract shows the highest inhibition zone recorded for Staphylococcus warneri. Furthermore, while the room temperature and $50{ }^{\circ} \mathrm{C}$ maceration extracts have similar effects against Bacillus cereus, the boiled aqueous extract shows the highest inhibition effect against these bacteria. It was reported that heating the aqueous extract of sumac fruits to $90{ }^{\circ} \mathrm{C}$ did not influence its antibacterial property (Gulmez et al., 2006).

Otherwise, results show that the room temperature extract has the same effect on each Enterobacter cloacae and Proteus vulgaris (Table 1); whereas Staphylococcus warneri is the most sensible strain to this extract followed by Bacillus cereus. Other works found, similarly to our findings, the important effect of inhibition of aqueous sumac extracts on Gram-positive bacteria compared to Gram-negative ones (Nasar-Abbas and Halkman, 2004). On the contrary of Gram-positive bacteria, the resistance of Gram-negative bacteria to the sumac extracts could be described by the richness of lipid in the membrane of these bacteria which make it resistant to the diffusion of water-soluble active compounds such as organic acids and tannins inside the bacterial (Sung et al., 2012).

Table 1. Antibacterial activity (diameter of inhibition zone) of aqueous extracts of species studied

\begin{tabular}{|c|c|c|c|c|c|}
\hline \multirow{2}{*}{ Species } & \multirow{2}{*}{ Extract type } & \multicolumn{4}{|c|}{ Diameter of inhibition zone $(\mathrm{mm})$} \\
\hline & & Bacillus cereus & Staphylococcus warneri & Proteus vulgaris & Enterobacter cloacae \\
\hline \multirow{5}{*}{ Sumac } & $\begin{array}{l}\text { Maceration at room } \\
\text { temperature }\end{array}$ & ${ }^{\mathrm{a}} 12.50 \pm 0.58^{\mathrm{C}}$ & ${ }^{\mathrm{a}} 16.88 \pm 1.03^{\mathrm{B}}$ & ${ }^{2} 7.88 \pm 0.63^{\mathrm{A}}$ & ${ }^{\mathrm{a}} 8.63 \pm 0.48^{\mathrm{A}}$ \\
\hline & Maceration at $50^{\circ} \mathrm{C}$ & ${ }^{\mathrm{a}} 12.13 \pm 0.86^{\mathrm{C}}$ & ${ }^{\mathrm{b}} 20.50 \pm 0.58^{\mathrm{B}}$ & ${ }^{\mathrm{b}} 00^{\mathrm{A}}$ & ${ }^{\mathrm{b}} 00^{\mathrm{A}}$ \\
\hline & Boiled aqueous & ${ }^{\mathrm{b}} 13.50 \pm 0.58^{\mathrm{C}}$ & ${ }^{\mathrm{a}} 16.38 \pm 0.48^{\mathrm{B}}$ & ${ }^{2} 7.38 \pm 0.48^{A}$ & ${ }^{\mathrm{a}} 8.13 \pm 0.63^{\mathrm{A}}$ \\
\hline & Penicillin & 25 & 35 & - & - \\
\hline & Gentamicin & - & - & 10 & 20 \\
\hline \multirow{5}{*}{ Rosemary } & $\begin{array}{l}\text { Maceration at room } \\
\text { temperature }\end{array}$ & ${ }^{\mathrm{a}} 9.75 \pm 0.65^{\mathrm{D}}$ & ${ }^{\mathrm{a}} 12.75 \pm 0.50^{\mathrm{C}}$ & ${ }^{\mathrm{a}} 8.00 \pm 0.70^{\mathrm{B}}$ & ${ }^{\mathrm{a}} 00^{\mathrm{A}}$ \\
\hline & Maceration at $50^{\circ} \mathrm{C}$ & ${ }^{\mathrm{a}} 9.63 \pm 0.48^{\mathrm{D}}$ & ${ }^{\mathrm{a}} 12.88 \pm 0.25^{\mathrm{C}}$ & ${ }^{\mathrm{a}} 8.00 \pm 0.00^{\mathrm{B}}$ & ${ }^{\mathrm{a}} 00^{\mathrm{A}}$ \\
\hline & Boiled aqueous & ${ }^{\mathrm{a}} 10.25 \pm 0.29^{\mathrm{D}}$ & ${ }^{\mathrm{a}} 12.25 \pm 0.50^{\mathrm{C}}$ & ${ }^{\mathrm{a}} 8.88 \pm 0.63^{\mathrm{B}}$ & ${ }^{\mathrm{a}} 00^{\mathrm{A}}$ \\
\hline & Penicillin & 25 & 35 & - & - \\
\hline & Gentamicin & - & - & 10 & 20 \\
\hline \multirow{5}{*}{ Cinnamon } & $\begin{array}{l}\text { Maceration at room } \\
\text { temperature }\end{array}$ & ${ }^{\mathrm{a}} 10.25 \pm 0.50^{\mathrm{C}}$ & ${ }^{\mathrm{a}} 14.88 \pm 0.85^{\mathrm{B}}$ & ${ }^{\mathrm{a}} 00^{\mathrm{A}}$ & ${ }^{\mathrm{a}} 00^{\mathrm{A}}$ \\
\hline & Maceration at $50^{\circ} \mathrm{C}$ & ${ }^{\mathrm{a}} 10.5 \pm 0.58^{\mathrm{D}}$ & ${ }^{\mathrm{a}} 16.5 \pm 1.23^{\mathrm{C}}$ & ${ }^{b} 7.25 \pm 0.50^{B}$ & ${ }^{\mathrm{a}} 00^{\mathrm{A}}$ \\
\hline & Boiled aqueous & ${ }^{\mathrm{a}} 10.63 \pm 0.75^{\mathrm{C}}$ & ${ }^{\mathrm{a}} 17.00 \pm 1.16^{\mathrm{B}}$ & ${ }^{\mathrm{a}} 00^{\mathrm{A}}$ & ${ }^{\mathrm{a}} 00^{\mathrm{A}}$ \\
\hline & Penicillin & 25 & 35 & - & - \\
\hline & Gentamicin & - & - & 10 & 20 \\
\hline \multirow{5}{*}{ Ginger } & $\begin{array}{l}\text { Maceration at room } \\
\text { temperature }\end{array}$ & ${ }^{\mathrm{a}} 00^{\mathrm{A}}$ & $8.75 \pm 0.96^{\mathrm{B}}$ & $7.75 \pm 0.29^{\mathrm{B}}$ & ${ }^{\mathrm{a}} 00^{\mathrm{A}}$ \\
\hline & Maceration at $50^{\circ} \mathrm{C}$ & ${ }^{2} 00^{A}$ & ${ }^{b} 7.25 \pm 0.50^{B}$ & ${ }^{b} 7.00 \pm 0.00^{B}$ & ${ }^{\mathrm{a}} 00^{\mathrm{A}}$ \\
\hline & Boiled aqueous & ${ }^{\mathrm{a}} 00^{\mathrm{A}}$ & $\mathrm{ab} 7.88 \pm 0.25^{\mathrm{B}}$ & ${ }^{\mathrm{C}} 0^{\mathrm{A}}$ & ${ }^{\mathrm{a}} 00^{\mathrm{A}}$ \\
\hline & Penicillin & 25 & 35 & - & - \\
\hline & Gentamicin & - & - & 10 & 20 \\
\hline
\end{tabular}

Each value represents mean $\pm \mathrm{SD}(\mathrm{n}=4)$. The same small letters in the same column for each species show no significant effects between extracts for the indicated strain at $\mathrm{p}<0.05$ according to Tukey. The same capital letters in the same line show no significant effects between bacterial strains for the indicated extract at $\mathrm{p}<0.05$ according to Tukey. 
Antibacterial activity of aqueous extracts of rosemary

While the three types of aqueous extracts of rosemary show no significant effect of inhibition on Enterobacter cloacae, the other studied strains are inhibited when exposed to rosemary extracts but with a similar effect of the extraction method $(\mathrm{P}<0.05)$ (Table 1$)$. On the other hand, results show a significant difference $(\mathrm{P}<0.05)$ among the bacteria for the same type of extract indicated; with Enterobacter cloacae among other studied strains is the most resistant, while Staphylococcus warneri is the most sensitive one (Table 1). The Gram-positive strains are then more sensitive than Gram-negative ones for rosemary aqueous extracts. These findings agree with results obtained by Moreno et al. (2006) who found that while water extract of rosemary exhibited an antibacterial activity against $S$. aureus (Gram-positive) it did not show any antibacterial activity against E. coli (Gram-negative) (Moreno et al., 2006).

\section{Antibacterial activity of aqueous extracts of cinnamon}

Results show no significant effect of extraction method on the antibacterial activity except the $50{ }^{\circ} \mathrm{C}$ maceration extract which demonstrates an inhibition against Proteus vulgaris (Table 1). On the other hand, findings show that Staphylococcus warneri is the most sensitive strain followed by Bacillus cereus (Table 1). The antimicrobial activity of cinnamon is generally attributed to its essential oils content. This could explain the low antibacterial activity of the aqueous extracts of cinnamon prepared in this study due to its low essential oils content. Similar results reported by Mukhtar and Ghori (2012) who revealed an antibacterial activity of aqueous extract of cinnamon (10-40\%, macerated at $\left.40-50{ }^{\circ} \mathrm{C}\right)$ against $B$. subtilis, whereas no effect was observed for E.coli (Mukhtar and Ghori, 2012).

\section{Antibacterial activity of aqueous extracts of ginger}

Results show no effect of the ginger aqueous extract on the antibacterial activity of Enterobacter cloacae and Bacillus cereus (Table 1). Otherwise, the room temperature and $50^{\circ} \mathrm{C}$ maceration extracts exhibit significant inhibitory effect against both Proteus vulgaris and Staphylococcus warneri compared to other extract types with a highly significant effect for the room temperature aqueous extract (Table 1). The low antibacterial activity of boiled water extract of ginger could be explained by the fact that some antibacterial components found in spice plants such as ginger are heat labile (Chen et al., 1985). The cold-water extract of ginger was reported to have an inhibition effect on both Staphylococcus aureus and Pseudomonas aeruginosa at different concentrations studied (Chrubasik et al., 2005).

Correlation between phenolic content and antibacterial activity of all types of plant extracts

In the present study, a correlation analysis was conducted to explore the relationships assumed between phenolic content and antibacterial activity of plant extracts studied using a regression analysis method. This analysis showed that the results of the phenolic content values don't correlate with the antibacterial activity found in our study (data not shown). From these findings we couldn't correlate the inhibition effect of extracts against the studied bacterial strains only with the presence of phenolic content in extracts. Essential oils (EOs) were described as the principal responsible for the antimicrobial activities in plants, herbs and spices (Tajkarimi et al., 2010). Another hypothesis to interpret the absence of defined correlation between the phenolic content and antibacterial activity could be explained by the reduced effectiveness attributed to the use of crude extracts instead of pure compounds, as these crude extracts generally contain flavonoids in glycosidic form where the sugar present in them decreases inhibition effectiveness against some bacteria (Negi, 2012).

On the other hand, a study found positive linear correlations between antibacterial activity and total phenolic content of 46 extracts from dietary spices and medicinal herbs (Shan et al., 2007). The $\mathrm{R}^{2}$ values were between 0.93 and 0.73 , and decreased in the following order: $S$. aureus $>$ B. cereus $>E$. coli $>S$. anatum $>L$. monocytogenes. This difference of results between our study and the latter study prove the arguments about the effect of extraction method on the potency of antibacterial activity of phenolic compounds. The extraction solvent of the latter work was $80 \%$ methanol that produced different active compounds extracted compared to our method. The identity of phenolic compounds extracted changes according to the solvent and the extraction factors applied. It was reported in literature that the acidified aqueous methanol solvent was very effective for the extraction of conjugate phenolic compounds (the major phenolics in plants) compared to other solvents (water, methanol, ethanol, acetone) used singly or in aqueous form (Wang et al., 2017).

\section{Antioxidant activity of aqueous extracts of plants \\ Total phenolic compounds content of extracts}

The content of the phenolic components of the studied spices differs according to both the extraction method and spice type (Table 2). The phenolic content of the studied plants was as follows: sumac > ginger > rosemary > cinnamon. These findings confirm with the results reported by Unver et al. (2009), who demonstrated that the total phenolic contents of sumac was higher than rosemary when extraction was conducted in mixture of $90 \%$ methanol + $9 \%$ water $+1 \%$ acetic acid at $24^{\circ} \mathrm{C}$ for $24 \mathrm{~h}$ (Ünver et al., 2009). Results show also that the room temperature aqueous extracts has the lowest content of phenolic compounds followed with a similar effect of both $50{ }^{\circ} \mathrm{C}$ maceration and boiled aqueous extracts (Table 2). This increase of the phenolic compounds with the increase of temperature could be explained by the fact that the temperature of extraction led to the increase of the liberation of some phenolic molecules from spice. On the other hand, the low content of phenolic content in heated extracts of cinnamon could be explained by the formation of gelatinous extract which led to difficulties in the filtration and maybe in the separation of phenolic compounds.

\section{Measurement of DPPH free-radical scavenging activity}

Results presented in Table 3 demonstrate an increase in the DPPH free-radical scavenging activity of sumac, rosemary and ginger extracts with the increase of the temperature of extraction. 
510

Table 2. The total phenolic content of different aqueous extracts of sumac, rosemary, cinnamon and ginger

\begin{tabular}{ccc}
\hline Species & Extraction method & $\begin{array}{c}\text { Phenolic content } \\
\left(\mathrm{mg} \mathrm{GAE} \mathrm{g}^{-1} \text { extract }\right)\end{array}$ \\
\hline Sumac & Maceration at room temperature & ${ }^{\mathrm{a}} 41.45 \pm 1.44^{\mathrm{A}}$ \\
& Maceration at $50^{\circ} \mathrm{C}$ & ${ }^{\mathrm{b}} 49.97 \pm 0.85^{\mathrm{A}}$ \\
\hline Rosemary & Boiled aqueous & ${ }^{\mathrm{b}} 51.63 \pm 0.96^{\mathrm{A}}$ \\
\hline \multirow{2}{*}{ Cinnamon } & Maceration at room temperature & ${ }^{3} 31.67 \pm 0.15^{\mathrm{B}}$ \\
& Maceration at $50^{\circ} \mathrm{C}$ & ${ }^{\mathrm{ab}} 34.34 \pm 1.54^{\mathrm{B}}$ \\
\hline & Boiled aqueous & ${ }^{\mathrm{b}} 37.08 \pm 0.48^{\mathrm{B}}$ \\
\hline Ginger & Maceration at room temperature & ${ }^{\mathrm{a}} 26.56 \pm 0.62^{\mathrm{C}}$ \\
& Maceration at $50^{\circ} \mathrm{C}$ & ${ }^{\mathrm{b}} 22.68 \pm 0.51^{\mathrm{C}}$ \\
\hline & Boiled aqueous & ${ }^{\mathrm{b}} 24.17 \pm 0.07^{\mathrm{C}}$ \\
\hline
\end{tabular}

Each value represents mean \pm SD $(n=4)$. The same small letters for the same species show no significant effects between extracts at $\mathrm{p}<0.05$ according to Tukey. The same capital letters show no significant effects between all species for the indicated extract type at $\mathrm{p}<0.05$ according to Tukey

Table 3. DPPH free-radical scavenging activity of different aqueous extracts of sumac, rosemary, cinnamon and ginger

\begin{tabular}{|c|c|c|}
\hline Species & Extraction method & DPPH free-radical scavenging activity (\%) \\
\hline \multirow{3}{*}{ Sumac } & Maceration at room temperature & ${ }^{a} 75.29 \pm 0.68^{A}$ \\
\hline & Maceration at $50^{\circ} \mathrm{C}$ & ${ }^{\mathrm{b}} 81.36 \pm 0.67^{\mathrm{A}}$ \\
\hline & Boiled aqueous & ${ }^{\mathrm{c}} 84.84 \pm 0.83^{\mathrm{A}}$ \\
\hline \multirow{3}{*}{ Rosemary } & Maceration at room temperature & ${ }^{\mathrm{a}} 69.24 \pm 0.19^{\mathrm{B}}$ \\
\hline & Maceration at $50^{\circ} \mathrm{C}$ & ${ }^{\mathrm{ab}} 71.75 \pm 1.74^{\mathrm{B}}$ \\
\hline & Boiled aqueous & ${ }^{\mathrm{b}} 74 \pm 0.01^{\mathrm{B}}$ \\
\hline \multirow{3}{*}{ Cinnamon } & Maceration at room temperature & ${ }^{\mathrm{a}} 38.17 \pm 0.70^{\mathrm{c}}$ \\
\hline & Maceration at $50^{\circ} \mathrm{C}$ & ${ }^{b} 32.95 \pm 1.32^{C}$ \\
\hline & Boiled aqueous & ${ }^{\mathrm{ab}} 34.70 \pm 1.36^{\mathrm{C}}$ \\
\hline \multirow{3}{*}{ Ginger } & Maceration at room temperature & ${ }^{2} 71.62 \pm 0.43^{D}$ \\
\hline & Maceration at $50^{\circ} \mathrm{C}$ & $b_{73} .95 \pm 0.09^{\mathrm{B}}$ \\
\hline & Boiled aqueous & ${ }^{\mathrm{c}} 76.10 \pm 0.15^{\mathrm{B}}$ \\
\hline
\end{tabular}

"Each value represents mean \pm SD

Same small letters show no significant effects between extracts for the indicated species at $\mathrm{p}<0.05$ according to Tukey.

Same capital letters show no significant effects between different species for the indicated extract at $\mathrm{p}<0.05$ according to Tukey.

Many parameters were generally reported to have an effect on the amount and composition of antioxidants in extracts such as solvent, ratio of solvent to product, temperature and extraction time (Makanjuola, 2017). However, the room temperature aqueous extract of cinnamon exhibits a higher value of DPPH inhibition than boiled aqueous with 38.17 and $34.70 \%$, respectively $(\mathrm{P}<$ $0.05)$. This dissimilarity in results between cinnamon and other spices could be due to the formation of gelatinous extract in the case of cinnamon which led to difficulties in filtration and maybe in the separation of antioxidant compounds like phenol compounds.

The potency of DPPH free-radical scavenging activity of the studied plants was as follows: sumac > ginger $\approx$ rosemary > cinnamon. Similar results showed that the antioxidant activity of sumac determined by DPPH method for the methanol/acetic acid/water extracts was higher than sage and rosemary (Ünver et al., 2009).

Determination of the oxidoreduction potential values

Oxidoreduction potential (or Eh) is used generally to determine the redox value of the medium/product. This value represents the sum of the total oxidant/reductant compounds found in the medium/product. The higher the oxidant compounds concentration is, the higher the Eh value of the medium is, and vice versa. The antioxidant activities of studied spices according to Eh method are as follows (Table 4): sumac > ginger > rosemary > cinnamon.

The $\mathrm{Eh}_{7}$ values of sumac extracts are lower (more reducing properties) than other spices (Table 4). This could be explained by the high phenolic content of sumac extracts compared to other plants that could confirm this hypothesis. Otherwise, the decrease of the $\mathrm{Eh}_{7}$ value is observed when the temperature of extraction increases except cinnamon. This maybe occurres due to the liberation of some reducing property molecules such as phenolic compounds especially flavonoids, vitamin $\mathrm{C}$ and molecules containing $-\mathrm{SH}$ group during the heating phase.

Correlation between DPPH assay and oxidoreduction potential values

The correlation coefficient $\left(\mathrm{R}^{2}\right)$ between DPPH assay and oxidoreduction potential values of the aqueous extracts of the studied plant was determined (Fig. 1A). Results show a good positive linear correlation between DPPH assay and oxidoreduction potential values $\left(\mathrm{R}^{2} \approx 0.96\right)$. 
Table 4. Oxidoreduction potential values of different aqueous extracts of sumac, rosemary, cinnamon and ginger

\begin{tabular}{ccc}
\hline Species & Extraction method & Oxidoreduction potential $(\mathrm{Eh} 7, \mathrm{mV})$ \\
\hline \multirow{2}{*}{ Sumac } & Maceration at room temperature & +63 \\
& Maceration at $50^{\circ} \mathrm{C}$ & +55 \\
\hline \multirow{2}{*}{ Rosemary } & Boiled aqueous & +52 \\
& Maceration at room temperature & +91 \\
\hline \multirow{2}{*}{ Cinnamon } & Maceration at $50^{\circ} \mathrm{C}$ & +88 \\
\hline & Boiled aqueous & +152 \\
\hline \multirow{2}{*}{ Ginger } & Maceration at room temperature & +180 \\
& Maceration at $50^{\circ} \mathrm{C}$ & +179 \\
\hline
\end{tabular}

When the value of DPPH scavenging activity of extracts increases, their Eh value decreases. For example, the lowest $\mathrm{Eh}_{7}$ value is for boiling extract of sumac with $+52 \mathrm{mV}$ and a $\mathrm{DPPH}$ value of $84.84 \%$; whereas, the highest $\mathrm{Eh}_{7}$ value is for $50{ }^{\circ} \mathrm{C}$ maceration of cinnamon with $+180 \mathrm{mV}$ and a DPPH value of $32.95 \%$ (Table 4). The antioxidant activity of extracts combines with the high content of bioactive molecules possessing low oxidoreduction potential values such as phenolic compounds, vitamin $\mathrm{C}$ and $\mathrm{E}$, molecules containing -SH group. These bioactive molecules with reducing properties are responsible for the decrease of Eh value of the medium.

Correlation between phenolic content assay and oxidoreduction potential values

To correlate the results obtained from the phenolic content assay and oxidoreduction potential methods, a regression analysis (correlation coefficient, $\mathrm{R}^{2}$ ) was performed (Fig. 1B). Results show a positive linear correlation between phenolic content values and oxidoreduction potential ones $\left(\mathrm{R}^{2} \approx 0.88\right)$. When the phenolic content of the extract increases its $E_{7}$ value decreases.

Good correlations were found between redox potential values and antioxidant properties using cyclic voltammetry method (Firuzi et al., 2005). Authors found an inverse correlation between FRAP assay and electrochemical measurement values, and they concluded that while good correlations were not found between the total number of hydroxyl groups of flavonoids and FRAP values $(\mathrm{R}=0.656)$ nor electrochemical values $(R=0.676)$, good correlations were found in the group of flavonols between these parameters $(R=0.96)$. Other researchers reported that the antioxidant activity of flavonoids is inversely proportional to their oxidoreduction values i.e. the lower oxidoreduction value of flavonoids is, the higher the antioxidant is (Yang et al., 2001). The results of the two latter reports are in agreement with our findings.

Correlation between phenolic content and DPPH activity values of plant extracts

When subjecting the results of DPPH scavenging activity and phenolic content for all plant extracts studied to the regression analysis, a high correlation coefficient was observed between the phenolic content and the DPPH scavenging activity (Fig. 1C). Results show a positive linear relationship between phenolic content and DPPH activity values for all types of plant extracts studied $\left(R^{2}=0.827\right)$ indicating that phenolic compounds are the major contributors to the antioxidant properties of these plants. A study reported that the contribution of the different phenolic groups reached $87 \%$ of the antioxidant activity in pomegranate juice (Gil et al., 2000). The latter finding was supported by another work in which the antioxidant capacity of tannins was reported to be 15-30 times more effective at quenching peroxyl radicals than simple phenolics or Trolox (Gil et al., 2000).

The linear reliability between the content of total phenolic compounds and the antioxidant activity of plant extracts has been similarly proved, like our finding, by some researchers. Wong et al (2006) reported a significant and linear correlation coefficient between the antioxidant activity and the total phenolic content in both aqueous $\left(\mathrm{R}^{2}\right.$ $=0.7917$, FRAP $)$ and methanol $\left(\mathrm{R}^{2}=0.7584\right.$, FRAP $)$ extracts of 30 Chinese medicinal plants, with phenolic compounds were thus a major contributor of antioxidant activity (Wong et al., 2006). Similarly, a positive significant and linear correlation between antioxidant activity and total phenolic content of aqueous and methanolic extracts of 112 traditional Chinese medicinal plants (all $\mathrm{R}^{2}$ values $\geq 0.95$, DPPH)(Cai et al., 2004), aqueous ethanol extracts of some Algerian medicinal plants $\left(\mathrm{R}^{2}=0.7931, \mathrm{DPPH}\right)(\mathrm{Djeridane}$ et al., 2006), Labiatae spice family $\left(\mathrm{R}^{2}=0.91\right.$, FRAP)(Wojdyło et al., 2007), aqueous extracts of 30 plant of industrial interest $\left(\mathrm{R}^{2}=0.939, \mathrm{DPPH} ; \mathrm{R}^{2}=0.966\right.$, ABTS and $\mathrm{R}^{2}=0.906$, FRAP)(Dudonné et al., 2009), methanolic extracts of Mediterranean herbs and aromatic plants $\left(\mathrm{R}^{2}=0.70-0.83, \mathrm{DPPH}\right)$, aqueous extracts of 70 medicinal plants $\left(\mathrm{R}^{2}=0.9825\right.$, FRAP $)($ Katalinic et al., 2006) was reported. These reports confirm the presence of significant linear correlation between the free radical scavenging activity determined by the DPPH, ABTS and FRAP methods, and total polyphenolic compounds (phenolic and flavonoids).

On the other hand, among three radical scavenging methods (Free radical scavenging activity, hydroxyl radical scavenging activity and superoxide anion scavenging activity) used to determine the scavenging activity of plants, the highest correlation coefficients were found between the phenolic content and the DPPH scavenging activity, followed by the hydroxyl radical scavenging activity (Parejo et al., 2002). 

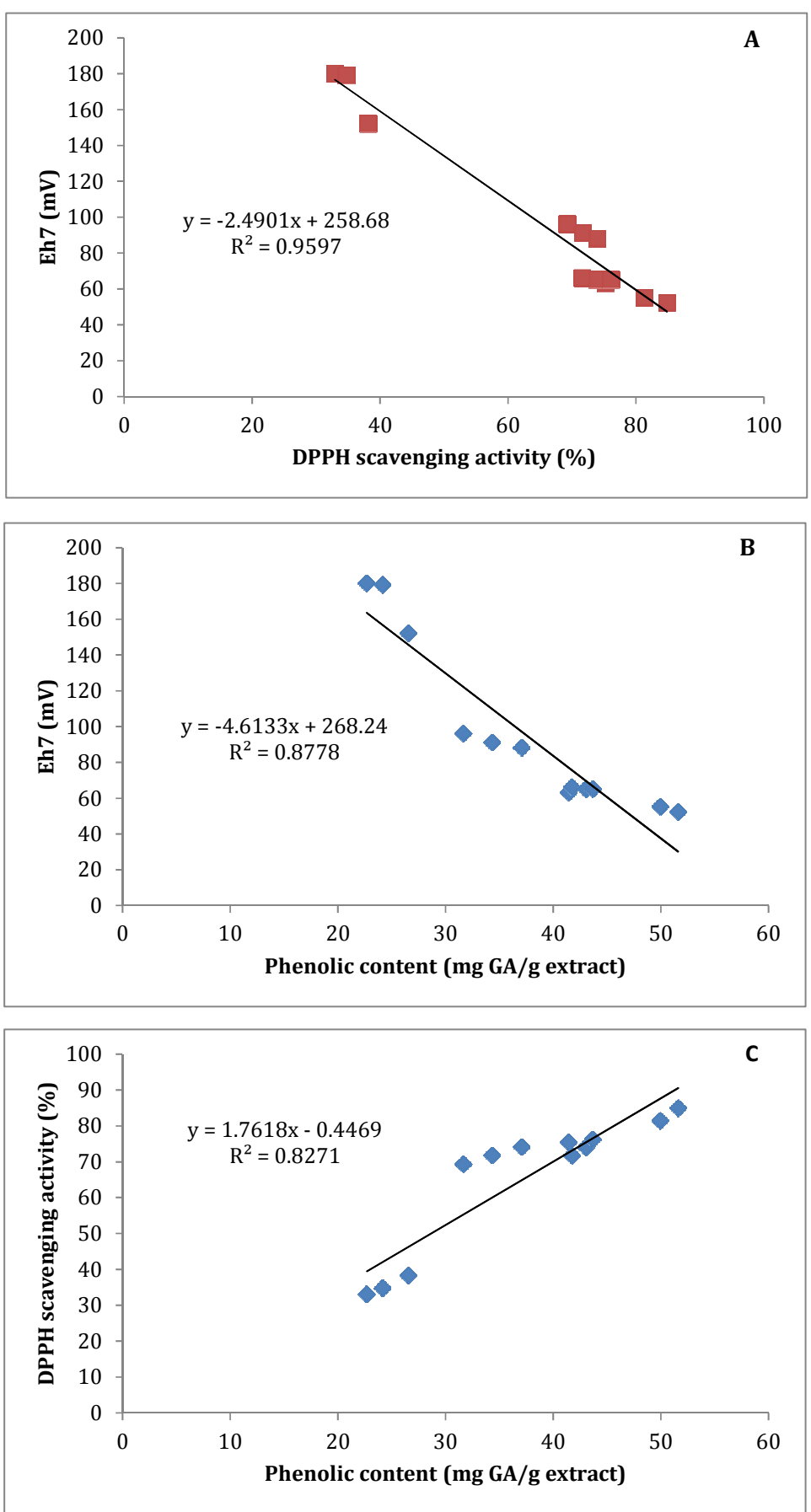

Fig. 1. Correlations between DPPH assay and oxidoreduction potential values (A), phenolic content and oxidoreduction potential values (B), and phenolic content and DPPH activity values (C) for all types of species extracts

This observation was confirmed by another study that demonstrated a weak correlation $\left(\mathrm{R}^{2}=0.58\right)$ between the phenolic content of different fruit juices and the total antioxidant activity estimated by the FRAP assay (Imeh and Khokhar, 2002).

The latter results elucidate the possibility of prediction of DPPH scavenging activity of a medium when its phenolic content is evaluated thanks to the ability of the two methods to donate hydrogen atoms (Katsube et al., 2004).
It is important to indicate that the Folin-Ciocalteu reagent used in the phenolic content assays exhibits an ability to react with other compounds such as vitamins (ascorbic acid, folic acid, folinic acid, NADH, pyridoxine, retinoic acid, thiamine and Trolox (ascorbic and retinoic acids has the greatest reactivity), amino acids (tyrosine, tryptophan and cysteine), thiols, inorganic ions $\mathrm{Fe}^{+2}, \mathrm{Mn}^{+2}$, $\mathrm{I}^{-}$and $\mathrm{SO}_{3}{ }^{-2}$ (Everette et al., 2010). Authors concluded that the Folin-Ciocalteu assay is a method of the determination of total antioxidant activity rather than phenolic content. 
Phenolics, known as the widest abundant antioxidants in most plants, are generally classified into non-soluble phenolic compounds such as tannins, cell-wall bound phenolic compounds such as hydroxycinammic acids, and soluble phenolic compounds such as phenolic acids, flavonoids and quinones (Rispail et al., 2005).

The aqueous extraction of active compounds from plants could be described as a good choice, such the case of our study, if we take into account the free fraction of phenolic compounds dissolved in water and possesses high antioxidant activities compared with the soluble conjugate and insoluble fractions that generally require an acidified organic solvent (Sun et al., 2012). Our findings could be also supported by another work where a positive correlation between antioxidant activity and total free phenolics $\left(\mathrm{R}^{2}=\right.$ 0.96 ) for seven cultivars of blueberry was found (Wang et al., 2017). The latter study reported that the total conjugated phenolics compounds significantly correlated with both DPPH and FRAP showing $\mathrm{R}^{2}$ value of 0.84 and 0.88 , respectively.

\section{Conclusions}

In the present study, it was observed that the Grampositive bacteria were more sensitive than Gram-negative bacteria toward the aqueous extracts of plant studied. It appears that the bioactive compounds extracted responsible for the antibacterial activity found in the aqueous extracts of the studied plant differ according to both the plant and extraction type. Nonlinear correlation has been observed between the phenolic content and the antibacterial activity of plant extracts prepared in this study. It was observed also that the antioxidant activity of the studied plants depends on the temperature of the extraction procedure. This increase in antioxidant activity was consistent with the increase of the phenolic content.

Many techniques have been developed to measure the antioxidant properties in food and biological systems using different methods such as the free radical scavenging activity, phenolic content and reducing/oxidizing capacity. Our finding proved a positive linear relationship between oxidoreduction potential values and those of both DPPH and phenolic content assays. Since previous studies advised at least two methods when screening the antioxidant activity of product (Schlesier et al., 2002), we can then recommend to combine the oxidoreduction potential measurement method (reducing/oxidizing power) with other different antioxidant techniques such as FRAP, ABTS and DPPH assays generally applied when the measurement of antioxidant properties of samples is considered. Combination of oxidoreduction potential measurement with these methods can be a useful and easy tool for valid assessment of antioxidant activity.

\section{Acknowledgements}

We thank Prof. Hiyam Bshara from the Faculty of Medicine at Homs University for supplying strains of microorganisms.

\section{References}

Alam MN, Bristi NJ, Rafiquzzaman M (2013). Review on in vivo and in vitro methods evaluation of antioxidant activity. Saudi Pharmaceutical Journal 21(2):143-152.

Alwazeer D, Delbeau C, Divies C (2003). Use of redox potential modification by gas improves microbial quality, color retention, and ascorbic acid stability of pasteurized orange juice. International Journal of Food Microbiology 89(1):21-29.

Cai Y, Luo Q, Sun M, Corke H (2004). Antioxidant activity and phenolic compounds of 112 traditional Chinese medicinal plants associated with anticancer.Life Sciences 74(17):2157-2184.

Chen HC, Chang MD, Chang TJ (1985). Antibacterial properties of some spice plants before and after heat treatment. Chinese Journal of Microbiology and Immunology 18(3):190-195.

Chrubasik S, Pittler MH, Roufogalis BD (2005). Zingiberis rhizoma: a comprehensive review on the ginger effect and efficacy profiles. Phytomedicine 12(9):684701.

Djeridane A, Yousfi M, Nadjemi B, Boutassouna D, Stocker P, Vidal N (2006). Antioxidant activity of some Algerian medicinal plants extracts containing phenolic compounds. Food Chemistry 97(4):654-660.

Dudonne S, Vitrac X, Coutiere P, Woillez M, Merillon J-M (2009). Comparative study of antioxidant properties and total phenolic content of 30 plant extracts of industrial interest using DPPH, ABTS, FRAP, SOD, and ORAC assays. Journal of Agricultural and Food Chemistry 57(5):1768-1774.

Everette JD, Bryant QM, Green AM, Abbey YA, Wangila GW, Walker RB (2010). Thorough study of reactivity of various compound classes toward the Folin-Ciocalteu reagent. Journal of Agricultural and Food Chemistry 58(14): 8139-8144.

Firuzi O, Lacanna A, Petrucci R, Marrosu G, Saso L (2005). Evaluation of the antioxidant activity of flavonoids by "ferric reducing antioxidant power" assay and cyclic voltammetry. Biochimica et Biophysica Acta (BBA) - General Subjects 1721(1-3):174-184.

Gil MI, Tomás-Barberán FA, Hess-Pierce B, Holcroft DM, Kader AA (2000). Antioxidant activity of pomegranate juice and its relationship with phenolic composition and processing. Journal of Agricultural and Food Chemistry 48(10):4581-4589.

Gulmez M, Oral N, Vatansever L (2006). The effect of water extract of sumac (Rhus coriaria $\mathrm{L}$.) and lactic acid on decontamination and shelf life of raw broiler wings. Poultry Science 85(8):1466-1471.

Imeh U, Khokhar S (2002). Distribution of conjugated and free phenols in fruits: antioxidant activity and cultivar variations. Journal of Agricultural and Food Chemistry 50(22):301-6306.

Jacob HE (1970). Redox potential. In: Norris JR, Ribbons DW (Eds). Methods in microbiology. Academic Press, London pp 92-121.

Katalinic V, Milos M, Kulisic T, Jukic M (2006). Screening of 70 medicinal plant extracts for antioxidant capacity and total phenols. Food Chemistry94(4):550-557.

Katsube T, Tabata H, Ohta Y, Yamasaki Y, Anuurad E, Shiwaku K, Yamane Y (2004). Screening for antioxidant activity in edible plant products: comparison of low-density lipoprotein oxidation assay, 
514

DPPH radical scavenging assay, and Folin-Ciocalteu assay. Journal of Agricultural and Food Chemistry 52(8):2391-2396.

Macheix J, Sapis J, Fleuriet A, Lee CY (1991). Phenolic compounds and polyphenoloxidase in relation to browning in grapes and wines. Critical Reviews in Food Science and Nutrition 30(4):441-486.

Makanjuola SA (2017). Influence of particle size and extraction solvent on antioxidant properties of extracts of tea, ginger, and tea-ginger blend. Food Science and Nutrition 5(6):1179-1185.

Mukhtar S, Ghori I (2012). Antibacterial activity of aqueous and ethanolic extracts of garlic, cinnamon and turmeric against Escherichia coli ATCC 25922 and Bacillus subtilis DSM 3256. International Journal of Applied Biology and Pharmaceutical Technology3(2):131-136.

Nasar-Abbas SM, Halkman AK (2004). Antimicrobial effect of water extract of sumac (Rhus coriaria L .) on the growth of some foodborne bacteria including pathogens. International Journal of Food Microbiology 97(1):63-69.

Negi PS (2012). Plant extracts for the control of bacterial growth: efficacy, stability and safety issues for food application. International Journal of Food Microbiology 156(1):7-17.

Parejo I, Viladomat F, Bastida J, Rosas-Romero A, Flerlage N, Burillo J, Codina C (2002). Comparison between the radical scavenging activity and antioxidant activity of six distilled and nondistilled Mediterranean herbs and aromatic plants. Journal of Agricultural and Food Chemistry 50(23):6882-6890.

Proestos C, Chorianopoulos N, Nychas G-JE, Komaitis M (2005). RPHPLC analysis of the phenolic compounds of plant extracts. Investigation of their antioxidant capacity and antimicrobial activity. Journal of Agricultural and Food Chemistry 53(4):1190-1195.

Rispail N, Morris P, Webb KJ (2005). Phenolic compounds: extraction and analysis. In: Lotusjaponicus handbook. Springer,Dordrecht pp 349-354.

Schlesier K, Harwat M, Böhm V, Bitsch R (2002). Assessment of antioxidant activity by using different in vitro methods. Free Radical Research 36(2):177-187.

Shahidi F, Zhong Y (2015). Measurement of antioxidant activity. Journal of Functional Foods 18:757-781.
Shan B, Cai Y-Z, Brooks JD, Corke H (2007). The in vitro antibacterial activity of dietary spice and medicinal herb extracts. International Journal ofFood Microbiology 117(1):112-119.

Singh RP, Chidambara Murthy KN, Jayaprakasha GK (2002). Studies on the antioxidant activity of pomegranate (Punica granatum) peel and seed extracts using in vitro models. Journal of Agricultural and Food Chemistry $50(1): 81-86$.

Sun L, Zhang H, Zhuang Y (2012). Preparation of free, soluble conjugate, and insoluble-bound phenolic compounds from peels of rambutan (Nephelium lappaceum) and evaluation of antioxidant activities in vitro. Journal of Food Science 77(2):C198-C204.

Sung SH, Kim KH, Jeon BT, CheongSH, ParkJH, Kim DH, Kweon HJ, Moon SH (2012). Antibacterial and antioxidant activities of tannins extracted from agricultural by-products. Journal of Medicinal Plants Research 6(15):3072-3079.

Tajkarimi MM, Ibrahim SA, Cliver DO (2010). Antimicrobial herb and spice compounds in food. Food Control 21(9):1199-1218.

Ünver A, Arslan D, Özcan MM, Akbulut M (2009). Phenolic content and antioxidant activity of some spices. World Applied Sciences Journal 6(3):373-377.

Wang M, Jiang N, Wang Y, Jiang D, Feng X (2017). Characterization of phenolic compounds from early and late ripening sweet cherries and their antioxidant and antifungal activities. Journal of Agricultural and Food Chemistry 65(26):5413-5420.

Wojdyło A, Oszmiański J, Czemerys R (2007). Antioxidant activity and phenolic compounds in 32 selected herbs. Food Chemistry 105(3):940949.

Wong C-C, Li H-B, Cheng K-W, Chen F (2006). A systematic survey of antioxidant activity of 30 Chinese medicinal plants using the ferric reducing antioxidant power assay. Food Chemistry 97(4):705-711.

Yang B, Kotani A, Arai K, Kusu F (2001). Estimation of the antioxidant activities of flavonoids from their oxidation potentials. Analytical Sciences 17(5):599-604. 